\title{
On the Principles and Target Mode of Overall Planning for the China Public Goods Supply
}

\author{
Meiying Yang \\ College of Economic and Management, Changchun University of Science and Technology \\ Changchun 130022, China \\ $\&$ \\ Business School, Jilin University, Changchun 130012, China \\ E-mail: yangmy996@139.com
}

Received: February 21, 2011

Accepted: March 14, 2011

doi:10.5539/jsd.v4n2p102

\begin{abstract}
Overall planning of the public goods supply is forming a kind of basic development tendency in the field of the public goods supply in China currently. Based on in-depth discussion of scientific connotation, practical significance and basic principles of overall planning for China public goods supply, the article further explores the target mode of overall planning supply of public goods.
\end{abstract}

Keywords: Public goods, Overall planning supply, Basic principle, Target mode

Public goods supply refers to a dynamic process that assigns public goods formed by certain subject organization to beneficiary groups through certain mechanism to meet social public needs (Yang Meiying, 2008). Currently the key to thoroughly apply the Scientific Outlook on Development in the field of China public goods supply lies in the realization of overall planning of the public goods supply. To realize overall planning of China public goods supply must deeply reveal the scientific connotation and practical significance, clearly define the basic principles of overall planning of China public goods supply, and explore the target mode to realize overall planning of China public goods supply.

\section{Scientific connotation and practical significance of overall planning for China public goods supply}

Overall planning of China public goods supply is a kind of development way to realize fair justice and balanced coordination for China public goods supply currently, which has both rich scientific connotation and important practical significance.

\subsection{The scientific connotation of overall planning of China public goods supply}

Overall planning of China public goods supply means a process that the government, as the subject of planning and guiding, according to the actual demands of the magnificent strategic target that completely builds well-to-do society to realize socialist modernization, starting from implementing comprehensively the scientific approach on the development, constructing a harmonious society of socialism and promoting sound and rapid development, aiming at the objective reality during the primary stage of Chinese socialism and the current situations of social public goods supply, following the intrinsic requirements of the development of China public goods supply, plans unify and guides scientifically the public goods supply, constantly dissolves interests contradictions and regulates the imbalance state, and satisfies the public needs in society with maximum limit, so as to achieve the high-quality, high-efficiency, coordinate and sustainable development. It includes four aspects of basic connotation as follows: firstly, the subject of overall planning of public goods supply is the government, which is generalized connation that not only refers to the state administrative departments, but also includes the national legislature and the judicial authority, and actually indicates the overall State power organs (Pu Xingzu, 2005). It is consist of Central People's Government and local people's governments at various levels. The government is the subject of overall planning for supply, which is not only decided by its functions of management society and public services, but also the specific situations of China. Secondly, overall planning is the fundamental way of public goods supply. Overall planning means unified planning, draw up an all-round scheme (Modern Chinese Dictionary, 2002) or making overall plans and taking all factors into consideration, which virtually is a diverse plan to realize reunification. This fundamental way is neither a uniform, equalitarianism, nor a policy partiality, falling on his side. But it implies overall, unified, coordinative and sustainable core and an important part of science development view. Thirdly, the aim of overall planning for China goods supply is to meet constantly increasing social public needs to the maximum, show fairness and justice, and realize social harmony. Overall planning for public goods supply makes various aspects of benefit relations in society well coordinated, contradictions among the people and other social contradictions well 
handled and social fairness and justice realistically maintained and realized. (Hu Jintao, 2007). Fourthly, the target of overall planning for China public goods supply is to realize high-quality, high-efficiency, coordinate and sustainable development of public goods supply. To well deal with the relationship among speed, benefit, quality and stability of development in the supply of public goods and better satisfy people's public benefit are the target of overall planning.

\subsection{The practical significance of overall planning of China public goods supply}

Currently, China is in new stage of development and critical period of reform and opening-up, completely constructing moderately well-off society, building a socialist harmonious society and accelerating socialist modernization. Overall planning of China public goods supply has important practical significance. Firstly, overall planning of China public goods supply is the objective need to thoroughly apply the Scientific Outlook on Development and realize good and fast development. The first point is to develop, the core is to be based on human being, the basic requirement is to have continuous development and the fundamental way is to overall plan in the Scientific Outlook on Development. Overall planning of China public goods supply is not only the important contents of realizing economic and social all-round development and important conditions of economic and social overall, coordinate and sustainable development, but specific application and vivid reflection of overall planning which is the fundamental way of the Scientific Outlook on Development in the field of public services. Secondly, overall planning of China public goods supply is an important path to build a socialist harmonious society and realize social equity and justice. Harmonious society is a society embodying democracy and legality, fairness and justice, honesty and friendship, vigor and security, maintenance of social order and concord between the nature and man. Overall planning of China public goods supply plays a role likes safety valve or stabilizer in finally shaping the situations that all the people enjoy their rights to education, employment, medical and age care, and housing, ensuring that all of the people share in the fruits of reform, and making various aspects of benefit relations in society well coordinated, contradictions among the people and other social contradictions well handled and social fairness and justice realistically maintained and realized. Thirdly, overall planning of China public goods supply is an important guarantee to realize the strategic target of completely constructing moderately well-off society and socialist modernization. Overall planning of China public goods supply is put forward based on the inner requirements of the development of current public goods supply and scientific judgment of the status and characteristics of economic and social development at the stage, which emphasize on solving the public problems with pronounced contradiction such as the gap between urban and rural areas, gaps within each region, social stratum structure, income distribution and employment, for example strive to build the social security system for both urban and rural residents so that everyone is assured of basic living standards; form a reasonable and orderly pattern of income distribution; there is a higher rate of employment; national education system becomes more perfect; everyone will have access to basic medical and health services, ext., which effectively ensures sustainable development of national economy and ultimate realization of the strategic target of comprehensive well-off society and socialist modernization.

\section{Basic principles that overall planning of China public goods supply should follow}

Clear basic principles that overall planning of China public goods supply should follow is the primary premise of building the target mode of overall planning for China public goods supply. According to the major idea of the seventeenth congress and the requirements of applying the Scientific outlook on development and building harmonious society, overall planning of China public goods supply should adheres to people-oriented principle, the principle of paying equal attention to efficiency and fairness, the principle of combination of generalization with particularity, the principle of relevance between entirety and localization, and the principle of uniform between periodicity and sustainability.

\subsection{Adhere to people-oriented principle}

Adhering to the people-oriented, taking the realization of people's comprehensive development as target, constantly meeting people's increasingly ceaselessly material and cultural needs and extending the benefits of economic development to all are the nature and core of the scientific outlook on development. To plan as a whole China public goods supply, plan unify and guides scientifically the public goods supply, constantly dissolve interests contradictions and regulate the imbalance state, and achieve comprehensive, coordinate and sustainable development of China public goods supply, should adhere to people-oriented principle. Firstly, in the process of overall planning of public goods supply, people-oriented principle should be applied to each chain of each guideline, policy, strategy and plan. Secondly, in the process of overall planning of public goods supply, people-oriented principle should be applied to public benefit that people pay the most attention to, ensuring basic existence and development benefit of most numerous people. Thirdly, in the process of overall planning of public goods supply, people-oriented principle should be applied to public decision-making mechanism so as to reflect the humanistic care and the democracy of participation.

\subsection{Adheres to the principle of paying equal attention to efficiency and fairness}

In the process of overall planning of China public goods supply, on the one hand, adhering to the principle of 
paying equal attention to efficiency and fairness means to attach more importance to efficiency principle. Through providing public goods, public resources obtain optimized allocation, which is conductive to the improvement of social economic efficiency and economic social healthy operation and development so that all the national people obtain maximized benefit and maximized social welfares are realized. On the other hand, adhering to the principle of paying equal attention to efficiency and fairness means to attach more importance to fairness. The distribution of benefit produced by public goods in each class should achieve fair state and fully reflect their public needs. Overall planning of China public goods supply must adhere to the principle of paying equal attention to efficiency and fairness, which is decided by the prominent contradictions in the stage in China and social economic development requirements and proposed based on other countries' experiences of public goods supply.

\section{3 adheres to the principle of uniform between periodicity and sustainability}

In the practice of overall planning of China public goods supply, to adhere to the principle of uniform between periodicity and sustainability refers to not only deal well with the new phenomena and problems shown in public goods supply in current historic stage, but also connects this with attaching more importance to bring the role of public goods supply for economic social sustainable development into play, which means to deal with the relationship between the short-term target and long-term target of public goods supply correctly and solve the problem of public goods supply appropriately. In the practice of overall planning of China public goods supply, only adhere to the principle of uniform between periodicity and sustainability, historic development cannot be cut off artificially, can based on the current focus on the future, step by step, from easy to difficult, make great effects to promote public goods supply and finally form the situations of comprehensive, coordinate and sustainable development.

\section{4 adheres to the principle of relevance between globality and locality}

The principle of relevance between globality and locality refers to in the process of overall planning of China public goods supply, not only command the whole situations and plan as s whole, but seize the main jobs, prominent contradictions and problems affecting global supply, especially public goods problems related to people's benefit and people's pressing concerns, make great effects to ensure the existence interests of the majority of people with breakthroughs made in key areas. In overall planning of China public goods supply, to adheres to the principle of relevance between globality and locality, is not only the basic requirements of dialectical materialism, but the objective needs of overall planning of China public goods supply. The practice of overall planning of China public goods supply has shown that if the principle of relevance between globality and locality is insisted well in the development of economic society, the society will become harmonious, otherwise, the society will fall into a unbalanced, incompatible and unsustainable state.

\section{5 adheres to the principle of combination of generalization with particularity}

To adheres to the principle of combination of generalization with particularity, refers to, in overall planning of China public goods supply, not only strive to realize equalization of basic public services, but adhere to adjust measures to local conditions and provide guidelines according to different categories, avoiding uniform and absolute equalitarianism. To adheres to the principle of combination of generalization with particularity in overall planning of China public goods supply is decided by China's practical situations and the historic development of public goods supply. On the one hand, China is a large country, and the urban and rural areas, each region has different natural endowment, development basis and social conditions; Meanwhile, the reform and opening-up has different influence on economic and social development, which decides China cannot develop simultaneously, synchronously at the same level recently. So the impact of such factors as technological level, natural resource, population density, the economic conditions in each region and urban and rural area, as well as the uneven distribution of consumption needs in China (or certain district), inevitably lead that each region and various classes in the country have tremendous differences to the needs of public goods.

\section{The target mode of overall planning of China public goods supply}

Overall planning of China public goods supply and to solve various problems of China public goods supply fundamentally, must on the basis of correct understanding of the practical situations and historic characteristics in new century and new stage of China, according to the basic requirements of apply the Scientific Outlook on Development and building a socialist harmonious society, build the target mode that government plans as a whole, government leads, multi-subjects supply, supply and demand dynamically and coordinately match, fairness and efficiency cooperate with sound system and perfect mechanism step by step.

\section{1 government plans as a whole}

Government plans as a whole, refers to the government, as the main body of planner, according to the needs of completely constructing moderately well-off society and the magnificent strategic target of realizing socialist modernization, starting from implementing comprehensively the scientific approach on the development, constructing a harmonious society of socialism, and promoting sound and rapid development of economy, following people-oriented principle, the principle of paying equal attention to efficiency and fairness, the 
principle of combination of generalization with particularity, the principle of relevance between globality and locality and the principle of uniform between periodicity and sustainability, aiming at objective reality during the primary stage of socialism in China and the current situations and practical problems of social public goods supply, based on the maximized satisfaction of social public demand which changes profoundly and the realization of the maximum of social public interests, adapts to the inner requirements of the development of China public goods supply and unified makes a plan for the supply of public goods in China. 1) define the position of the government as main body in planning public goods supply, aim at objective reality during the primary stage of socialism in China and the current situations and practical problems of social public goods supply, based on the realization of the maximum of social public interests, adapts to the inner requirements of the development of China public goods supply and unified makes a plan for the supply of public goods in China; 2) aim at national conditions and powers during the primary stage of socialism in China and the current situations and practical problems of social public goods supply, at macroscopic level, work out a comprehensive development plan or strategy of public goods supply which fits public needs and the needs of national economy and social development in the long term. 3) combined with the practice of local economic construction and social development, work out scientific, comprehensive and effective guidelines and specific measures of plan implementation, and formulate rules, innovation mechanism, stress on regulating through related laws or provisions, to ensure gradual realization of development target and development strategy. 4) unified plan the policy and concept guideline of public goods supply and build long-term mechanism of overall planning for China public goods supply.

\section{2 government leads, multi-subjects develop together}

What's called the government leads, multi-subjects develop together, is overall planning of public goods supply must build the major structure that the government leads, multi-subjects develop together, which means that under the premise of insisting on government-lead, the roles of social organizations, international organizations and private departments are brought into play so as to form the multi-subject in public goods supply which each subject has its role and duty, mutually complement, mutual promotion, develop together. This not only defines the responsibilities of the government, avoiding the government overrun, mismatches and is absent from their duties because of unclear positions in the public goods supply, but also is an important arrangement and premise that defines the boundary of the government and other suppliers in order to realize the structure that each subject has its role and duty, mutually complement, mutual promotion, develop together. It emphasizes on leading the development direction of public goods supply and brings the role of subjects such as social organizations, international organizations and private departments into play. In realizing the target that each subject has its role and duty, mutually complement, mutual promotion, develop together, they undertake the responsibilities of guiding and regulating, make up market failure, provide the public goods such as national defense, safety, administration and creating, cultivating and regulating market development, meanwhile, they focus on the needs of entire interests, long-term interests and fundamental interests and supply the public goods which others cannot provide or cannot provide effectively but is related to economic social development. While insisting on the subjective position of the government, multi-subjects are developed positively, private departments, social organizations and other non-governmental departments are advocated and encouraged to enter the field of public goods supply, in order to realize each subject has its role and duty, mutually complement, mutual promotion, develop together.

\section{3 sound system and perfect mechanism}

Sound system means that overall planning of public goods supply must take sound system as guarantee, based on specific situations in China, directing at adapting to the needs of China's public demand development, so as to realize fundamental conversion from management to service, from unlimited to limited, from centralized government functions to decentralized government functions. To realize the fundamental conservation, political restructuring must be promoted, governmental supply concept and mode must be converted, and reasonable separation of powers between the government and local government is realized, which creates necessary conditions for transforming the government functions. Meanwhile, unceasingly deepen the economic restructuring and build a serious of perfect laws and regulations related to overall planning of social public goods supply, laying economic systematic and legal systematic basis for overall planning of China public goods supply. Perfect mechanism means that overall planning of public goods supply should build various mechanisms including compulsory mechanism of the government, voluntary mechanism of the market and volunteer mechanism of social organizations, which are dynamically coordinate and mutually complementary with perfect functions. To build this kind of mechanism system, firstly, it should accelerate the realization of the conversion of public goods supply mechanism from monothetic government supply mechanism to compound mechanism combined compulsory mechanism of the government, voluntary mechanism of the market with volunteer mechanism of social organizations; secondly, it should build a kind of effective section and mutually coordinate mechanism among imperfect real government, imperfect real market and undeveloped social organizations. According to economic rationality principle of resource optimization allocation and transaction cost minimization principle, we strive for seeking the equilibrium point among the government, market and social 
organizations in the field of public goods supply, build diverse system that the government, market and society provide public goods and multi-subjects mechanism and complementary mechanism of public goods supply.

3.4 Supply and demand dynamically and coordinately match, fairness and efficiency cooperate with each other

What's called supply and demand dynamically and coordinately match refers to in the process of public goods supply, more attention should be paid to the relationship between public demand and supply currently as well as in the future, so as to realize deep but not superficial coordinate state between demand and supply of public goods from multi-fields, multi-dimensions and multi-levels. Firstly, harmonious matching in the contents of demand and supply: In the public goods supply, public goods supply tries to agree with demand in contents basically. Secondly, harmonious matching in the space of demand and supply: Not only macroscopically regional distribution demand of public goods is satisfied, the supply and demand orientation of public goods in rural and urban area is adjusted in time and different classes' appeals for supply and demand of public goods in society should be concerned, but also microscopically the structure of public goods supply should be optimized constantly in order to realize the coordination between supply and demand; meanwhile in the space of supply and demand, the diversity of supply subjects structure, fairness of public investment structure and policies should be realized gradually and the contradictions such as subject omission, achievement-oriented supply and discriminatory double-standard supply are dissolved constantly. Finally, harmonious matching in the time of demand and supply: For social existence and sustainable development, public goods supply not only satisfies current dominant public demand but also prospective implicit public demand which adapts to the needs in the future. The cooperation between airness and efficiency means to realize dynamic and optimized combination of fairness and efficiency targets, according to social specific situations in different stages, in the process of overall planning of China public supply, in order to achieve mutual improvement and their inner unity in the process of development. It virtually emphasizes on paying equal attention to fairness and efficiency. There are various ways of combination of fairness with efficiency as follows: give priority to efficiency with due consideration to fairness; pay equal attention to fairness and efficiency; equal emphasis on efficiency and fairness; efficiency and fairness are considered simultaneously; pay attention to fairness and efficiency. In different historic stages of social development, they have corresponding different focuses, and the ways are flexible and dynamic. Current focus should realize the transition from that give priority to efficiency with due consideration to fairness to the optimized combination of fairness with efficiency gradually.

\section{References}

Central CCP's resolution on several great issues of building harmonious society. Beijing: People's Publishing House. 2006. 5.

Hu, Jintao. (2007). Hold High the Great Banner of Socialism with Chinese Characteristic and Strive for New Victories in Building a Moderate Prosperous Society in all Respects. People's Publishing House, 2007. 15.

Modern Chinese Dictionary. (2002). Beijing: Commercial Press, pp. 1267.

$\mathrm{Pu}$, Xingzu. (2005). political system of the People's Republic of China. Shanghai: Shanghai People's Publishing House, pp. 233.

Qi, Chao. (2009). My opinion of the implication and essence of a system. Taxation and economy. 2009(3).

Selected important literature since the sixteenth National Congress. Beijing: People's Publishing House, pp. 706.

Yang, Meiying. (2008). Research on overall planning China public good supply. Changchun: Northeast Normal University. 